\title{
Adrenomedullin binding improves catecholamine responsiveness and kidney function in resuscitated murine septic shock
}

Katja Wagner ${ }^{1}$, Ulrich Wachter ${ }^{1}$, Josef A Vogt ${ }^{1}$, Angelika Scheuerle ${ }^{2}$, Oscar McCook', Sandra Weber ${ }^{1}$, Michael Gröger ${ }^{1}$, Bettina Stahl', Michael Georgieff ${ }^{1}$, Peter Möller ${ }^{2}$, Andreas Bergmann ${ }^{3}$, Frauke Hein ${ }^{3}$, Enrico Calzia ${ }^{1}$, Peter Radermacher ${ }^{1 *}$ and Florian Wagner $^{1}$

\author{
* Correspondence: \\ peter.radermacher@uni-ulm.de \\ ${ }^{1}$ Sektion Anästhesiologische \\ Pathophysiologie und \\ Verfahrensentwicklung, Klinik für \\ Anästhesiologie, Ulm 89081 \\ Germany \\ Full list of author information is \\ available at the end of the article
}

\begin{abstract}
Purpose: Adrenomedullin (ADM) has been referred to as a double-edged sword during septic shock: On one hand, ADM supplementation improved organ perfusion and function, attenuated systemic inflammation, and ultimately reduced tissue apoptosis and mortality. On the other hand, ADM overproduction can cause circulatory collapse and organ failure due to impaired vasoconstrictor response and reduced myocardial contractility. Since most of these data originate from un-resuscitated shock models, we tested the hypothesis whether the newly developed anti-ADM antibody HAM1101 may improve catecholamine responsiveness and thus attenuate organ dysfunction during resuscitated murine, cecal ligation and puncture (CLP)-induced septic shock.
\end{abstract}

Methods: Immediately after CLP, mice randomly received vehicle (phosphate-buffered saline, $n=11)$ or HAM1101 $\left(n=9 ; 2 \mu \mathrm{g} \cdot \mathrm{g}^{-1}\right)$. Fifteen hours after CLP, animals were anesthetized, mechanically ventilated, instrumented, and resuscitated with hydroxyethylstarch and continuous i.v. norepinephrine to achieve normotensive hemodynamics (mean arterial pressure $>50$ to $60 \mathrm{mmHg}$ ).

Results: HAM1101 pretreatment reduced the norepinephrine infusion rates required to achieve hemodynamic targets, increased urine flow, improved creatinine clearance, and lowered neutrophil gelatinase-associated lipocalin blood levels, which coincided with reduced expression of the inducible nitric oxide synthase and formation of peroxynitrite (nitrotyrosine immunostaining) in the kidney and aorta, ultimately resulting in attenuated systemic inflammation and tissue apoptosis.

Conclusions: During resuscitated murine septic shock, early ADM binding with HAM1101 improved catecholamine responsiveness, blunted the shock-related impairment of energy metabolism, reduced nitrosative stress, and attenuated systemic inflammatory response, which was ultimately associated with reduced kidney dysfunction and organ injury.

Keywords: Cecal ligation and puncture; Creatinine clearance; Neutrophil gelatinaseassociated lipocalin; Inducible nitric oxide synthase; Endothelial nitric oxide synthase; Peroxynitrite; Apoptosis

\section{Springer}

(c) 2013 Wagner et al.; licensee Springer. This is an Open Access article distributed under the terms of the Creative Commons Attribution License (http://creativecommons.org/licenses/by/2.0), which permits unrestricted use, distribution, and reproduction in any medium, provided the original work is properly cited. 


\section{Introduction}

Adrenomedullin (ADM) has been referred to as a double-edged sword in sepsis [1]: during cecal ligation and puncture (CLP)- [2-4], endotoxin- [5], or Staphylococcus aureus $\alpha$-toxin-induced sepsis [6], ADM administration restored organ perfusion during the hypodynamic shock phase. This effect coincided with attenuated systemic inflammation [7], decreased activation of the inducible nitric oxide synthase (iNOS) and peroxynitrite formation [8], and reduced organ dysfunction [9], apoptosis [10], and mortality [6]. ADM release is therefore referred to as a protective adaption to systemic inflammation [11] and circulatory shock [12]. Nevertheless, its overproduction may cause circulatory collapse and organ failure [13] due to peripheral vasodilation [14]: arterial hypotension and reduced systemic vascular resistance correlated with increased ADM concentrations in volunteers injected with endotoxin [15] and patients with sepsis [16]. Moreover, ADM levels were directly related to morbidity and mortality [17-21], and persistently high concentrations allowed predicting infectious complications after septic shock [22]. The ADM-related hypotension results from excess NO release with impaired vasoconstrictor response [23,24] and myocardial contractility [25]. In un-resuscitated shock, ADM antagonists reversed these effects and ultimately improved survival $[24,25]$. Hollenberg et al., however, showed that survival of wild-type and $\mathrm{iNOS}^{-/-}$mice after CLP-induced sepsis only differed when adequate resuscitation was provided [26]. Therefore, we tested the hypothesis whether a newly developed ADM antibody may improve catecholamine responsiveness and attenuate kidney dysfunction in resuscitated, CLP-induced septic shock [27].

\section{Materials and methods}

\section{Anesthesia, surgical instrumentation, and experimental protocol}

The study protocol was approved by the University Animal Care Committee and the federal authorities for animal research of the Regierungspräsidium Tübingen, BadenWürttemberg. A total of 23 male C57BL/6J mice (body weight 23 to $29 \mathrm{~g}$, age 10 to 16 weeks) were used for the experiments, which were performed in adherence to the National Institutes of Health Guidelines on the Use of Laboratory Animals. Animals which did not undergo mechanical ventilation and surgical instrumentation served as controls for the assessment of blood ADM levels $(n=4)$ and tissue immune blotting and gel shifts $(n=6)$. Immediately after CLP, mice randomly received vehicle (phosphate-buffered saline (PBS), $n=11$ ) or the anti-ADM antibody HAM1101 ( $n=12$; $2 \mu \mathrm{g} \cdot \mathrm{g}^{-1}$ to achieve antibody concentrations $>4 \mu \mathrm{g} \cdot \mathrm{mL}^{-1}$, i.e., to guarantee plasma antibody levels two orders of magnitude in excess of ADM concentrations). HAM1101 is an antibody directed to the $\mathrm{N}$-terminal part of ADM and was chosen because, in pilot experiments, it had significantly improved 14-day survival after CLP in mice $(n=10)$ with otherwise $100 \%$ mortality within two (vehicle PBS) and three (control antibody) days. Three animals were excluded: at necropsy and organ removal, one animal presented with pronounced intra-abdominal and retroperitoneal bleeding, and in the two other animals, by accident, the antibody preparation was not adequately stored within the specifications. Therefore, statistical analysis in the HAM1101 group refers to $n=9$. The anesthesia, CLP procedure, and the surgical instrumentation have been described in detail previously [27]. Mice were anesthetized with sevoflurane and s.c. buprenorphine 
together with acetated Ringer's solution containing glucose. A midline laparotomy cecum ligation and a single puncture (18-gauge needle) were performed. After squeezing to expel a stool, the cecum was returned into the abdominal cavity. Postoperatively, water and food were provided ad libitum. After $8 \mathrm{~h}$, mice received a second s.c. injection as described above together with buprenorphine, ceftriaxon, and clindamycine. Fifteen hours post-CLP, mice were anesthetized with sevoflurane, i.p. ketamine, midazolam, and fentanyl. After placement of the animal on the procedure bench equipped with heating pads and lamps, a rectal temperature probe was inserted. The anterior neck was incised to expose the trachea, the right internal jugular vein, and the right carotid artery. The trachea was intubated, and the lungs were mechanically ventilated with a pressure-controlled, lung-protective ventilation strategy using a small animal ventilator (FlexiVent ${ }^{\mathrm{TM}}$, Scireq ${ }^{\circ}$, Montreal, Canada) [28]. After a lung recruitment maneuver, respirator settings were as follows: $\mathrm{FiO}_{2}=0.5$, tidal volume $=6$ to $8 \mu \mathrm{L} \cdot \mathrm{g}^{-1}$, respiratory rate $=160$ breaths $\cdot \mathrm{min}^{-1}$, inspiratory/expiratory time ratio $=1: 2$, and PEEP $=5 \mathrm{~cm} \mathrm{H}_{2} \mathrm{O}$. Catheters were inserted into the jugular vein, the carotid artery, and the bladder. Anesthesia was maintained with continuous i.v. ketamine, fentanyl, and midazolam, titrated to reach deep sedation and analgesia as documented by complete tolerance against noxious stimuli. Normoglycemia was maintained by i.v. glucose (stable, non-radioactive labeled $1,2,3,4,5,6-{ }^{13} \mathrm{C}_{6}$-glucose and unlabeled glucose, $0.5 \mathrm{mg} \cdot \mathrm{g}^{-1} \cdot \mathrm{h}^{-1}$ each). Normotensive hemodynamics (i.e., mean arterial pressure $>50$ to $60 \mathrm{mmHg}$ ) were achieved by i.v. hydroxyethylstarch (maximum infusion rate $20 \mu \mathrm{L} \cdot \mathrm{g}^{-1} \cdot \mathrm{h}^{-1}$ ) and, if needed, together with norepinephrine. After $5 \mathrm{~h}$, animals were killed through blood withdrawal via the $\mathrm{V}$. cava inferior.

\section{Nitrate, cytokine, and chemokine concentrations}

As a surrogate for $\mathrm{NO}$ production, plasma nitrite + nitrate $\left(\mathrm{NO}_{2}^{-}+\mathrm{NO}_{3}^{-}\right)$levels were measured using chemiluminescence after reduction to $\mathrm{NO}$ with vanadium chloride (NOA 280 NO Analyzer, Sievers Medical Instruments, Boulder, CO, USA) [29]. Plasma tumor necrosis factor (TNF)- $\alpha$, interleukin (IL)-6, monocyte chemoattractant protein (MCP)-1, and keratinocyte-derived chemokine (KC) concentrations were determined using a mouse multiplex cytokine kit (Bio-Plex Pro Cytokine Assay, Bio-Rad, Hercules, CA, USA). The assay was performed by using the Bio-Plex suspension array system according to the manufacturer's instructions $[27,28]$. Levels below the detection limit of the assays were set to zero for statistical purposes.

\section{Adrenomedullin assay and adrenomedullin antibody (HAM1101) preparation}

The detailed description is presented as an Additional file 1. Briefly, plasma ADM (both free and antibody-bound ADM in the HAM1101 group) concentrations were measured with a sandwich coated tube luminescence immunoassay, based on acridinium NHSester labeling and anti-mouse ADM antibodies (MAM). Dilutions of mouse adrenomedullin (mADM) and subsequently the labeled tracer MAM1301 were added to MAM1201-coated tubes. After washing of unbound tracer, chemiluminescence was measured (AutoLumat LB 953 Berthold Technologies, Bad Wildbad, Germany). For antibody preparation, murine and human ADM peptides were synthesized (JPT Technologies, Berlin, Germany) with an additional N-terminal cysteine (if no cysteine is 
present within the selected adrenomedullin sequence) residue for conjugation of the peptides to bovine serum albumin using SulfoLink-coupling gel (Perbio Science, Bonn, Germany). HAM1101 blood concentrations were quantified via competitive immunoassay employing chemoluminescence-labeled HAM1101 as tracer and ADM in the solid phase.

\section{Creatinine, urea, and neutrophil gelatinase-associated lipocalin}

Blood neutrophil gelatinase-associated lipocalin (NGAL) concentrations were measured using a commercial ELISA (mouse NGAL, RUO 042, BioPorto Diagnostics A/S, Gentofte, Denmark). Urea and creatinine concentrations were quantified with a capillary column (Optima-5MS, Macherey-Nagel, Düren, Germany) gas chromatography/ mass spectrometry system (Agilent 5890/5970, Böblingen, Germany) using ${ }^{2} \mathrm{H}_{3}$-creatinine (CDN isotopes, Pointe-Claire, QU, Canada) and methylurea (Fluka Chemikalien, Buchs, Switzerland) as internal standards. After deproteinization with acetonitrile and evaporation to dryness, the supernatant was reconstituted in formic acid and extracted over a weak anion exchange column (WCX, Phenomenex, Aschaffenburg, Germany). Acetonitrile plus $N$-(tert-butyldimethylsilyl)- $N$-methyltrifluoroacetamide and $\mathrm{N}, \mathrm{O}$-bis(trimethylsilyl)trifluoroacetamide allowed formation of the urea tertbutyl-dimethylsilyl- and the creatinine trimethylsilyl-derivatives, respectively. Ions $\mathrm{m} / \mathrm{z} 231$ and 245, and m/z 329 and 332 were monitored for urea and creatinine analytes and internal standards. Creatinine clearance was derived from urine output and plasma and urine creatinine concentrations.

\section{Glucose metabolism}

Parameters of glucose metabolism were determined using gas chromatography/mass spectrometry [30]. After conversion of glucose to a penta-trifluoroacetyl derivative, endogenous glucose production rate was calculated from the blood ${ }^{13} \mathrm{C}_{6}$-glucose isotope enrichment. Whole-body glucose oxidation was derived from the total $\mathrm{CO}_{2}$ production and the ${ }^{13} \mathrm{CO}_{2} /{ }^{12} \mathrm{CO}_{2}$ isotope ratio in the mixed expiratory gas.

\section{Cell extracts, electrophoretic mobility shift assay, immunoblots, and comet assay}

Immediately postmortem, the right kidney was removed, homogenized, and lysed in lysing buffer. Cells were resuspended and lysed on ice. To assess the expression of heme oxygenase-1 (HO-1), activated caspase-3, and BcL-xL, equal total protein aliquots (20 to $60 \mu \mathrm{g}$ ) were separated by SDS-PAGE and transferred by Western blotting. After blocking, the membranes were incubated with primary antibodies (anti HO-1, Stressgen; anti-Bcl-xL, anti-cleaved caspase-3, Cell Signaling, Danvers, MA, USA). The primary antibodies were detected using horseradish peroxidase-conjugated secondary antibodies (Cell Signaling or Santa Cruz, Heidelberg, Germany). The membranes were subjected to chemiluminescence using the SuperSignal West Femto Maximum Sensitivity Substrate (Thermo Scientific, Ulm, Germany). Exposed films were scanned, and intensity of immunoreactivity was measured using NIH ImageJ software (http:// rsb.info.nih.gov/nih-image). Activation of the nuclear transcription factor $\kappa B$ (NF- $\kappa B$ ) was determined using an electrophoretic mobility shift assay (EMSA) [27,28]: cell extracts were incubated with poly-doxy-inosinic-deoxy-cytidylic acid (poly-dI-dC) and ${ }^{32} \mathrm{P}$-labeled 
double stranded oligonucleotide containing the NF-кB (НIVкB-site) (5' -GGATCCTCAA CAGAGGGGACTTTCCGAGGCCA-3'). Complexes were separated in polyacrylamide gels and exposed to X-ray films. A phosphorimager and image analysis software allowed quantifying the radioactively labeled NF-kB. Relating the intensity of each band to that of control animals loaded simultaneously allowed for comparison between individual gels. Protein expression and NF- $\mathrm{kB}$ activation are presented as $x$-fold increase over control values.

Single cell gel electrophoresis allowed assessing the oxidative deoxyribonucleic acid (DNA) damage ('tail moment' in the alkaline version of the comet assay) [30]. Immediate postmortem biopsies were placed in buffer containing Na-ethylenediaminetetraacetic acid and minced to obtain a cell suspension. Two agarose gel slides were prepared from each biopsy. The mean tail moment of 100 nuclei analyzed per slide was used for each animal.

\section{Histology}

Immediately postmortem, the left kidney was removed, sectioned by a sagittal cut, and fixed in paraformaldehyde for histopathological examination by an experienced pathologist (A.S.) blinded for the sample grouping. Paraffin sections were stained with hematoxylin and eosin and periodic acid-Schiff staining; photomicrographs were taken of three sampling areas from each section. Glomerular histopathological alterations were analyzed for glomerular tubularization, i.e., the herniation of proximal tubular epithelial cells into Bowman's capsule [31]. Data are expressed as the number of glomeruli showing glomerular tubularization in percentage of all glomeruli analyzed (outer cortical region 30, medullar region 20 glomeruli) of the three random sections. Tubular histopathological damage was assessed as intraluminal protein cylinders and necrosis.

Immunohistochemistry for nitrotyrosine and the inducible nitric oxide synthase

The descending thoracic aorta was excised down to the diaphragm, fixed in paraformaldehyde, and embedded in paraffin. Sections of the aorta and the left kidney were dewaxed in xylene, rehydrated with ethanol, incubated in citrate buffer, brought to boiling for heat-induced antigen retrieval, and blocked with goat sera before incubation with rabbit anti-nitrotyrosine 1:250 (Millipore \#-AB5411, Schwalbach, Germany), antieNOS (eNOS BD\# 610297, Beckton Dickinson, Heidelberg, Germany), and anti-iNOS (Santa Cruz \#sc-651). Primary antibody detection was performed with anti-rabbit Dako Real detection system alkaline phosphatase red (Dako \#K5005, Copenhagen, Denmark). Slides were visualized using a Zeiss Axio Imager A1 microscope. Five artery and three kidney sections were quantified for intensity and area of the immune-reactive regions using the AxioVision (rel. 4.8) software (Zeiss, Jena, Germany). Results are presented as arbitrary units of densitometric sum red.

\section{Statistical analysis}

All data are presented as median (range). After exclusion of normal distribution using the Kolmogorov-Smirnov test, differences between groups were analyzed with a one-way Kruskal-Wallis analysis of variance on ranks followed by a post hoc Dunn test. Because of the multiple statistical testing resulting from the numerous variables measured, all results have to be interpreted in an exploratory rather than confirmatory manner. 


\section{Results}

Plasma ADM concentrations in mice without mechanical ventilation and surgical instrumentation were $7(4,11) \mathrm{pg} \cdot \mathrm{mL}^{-1}$. HAM1101 tended to attenuate the CLP-induced increase in ADM levels, however, without reaching statistical significance ( $p=0.094$; Table 1). The total, i.e., crystalloid plus colloid, fluid infusion rate was identical (vehicle $48(47,50)$, HAM1101 $\left.47(46.49) \mu \mathrm{L} \cdot \mathrm{g}^{-1} \cdot \mathrm{h}^{-1}, p=0.185\right)$ in the two groups. All animals needed continuous i.v. noradrenaline to achieve hemodynamic targets, and HAM1101 was associated with significantly lower mean infusion rates during the 5 -h observation period $\left(0.010(0.09,0.012)\right.$ vs. $\left.0.019(0.016,0.24) \mu \mathrm{g} \cdot \mathrm{g}^{-1} \cdot \mathrm{h}^{-1}, p<0.001\right)$. In all 23 animals taken together, i.e., also taking into account the three animals excluded from the detailed statistical analysis, there was a significant linear relationship between the ADM blood levels and the noradrenaline infusion rates (Pearson coefficient of correlation $r^{2}=0.574, p<0.001$ ) (Figure 1).

Hemodynamics, gas exchange, acid-base status, glycemia, endogenous glucose, or total $\mathrm{CO}_{2}$ production did not differ between the two groups (Table 2). However, HAM1101 lowered lactatemia and increased direct, aerobic glucose oxidation until the end of the experiment. HAM1101 was associated with three- and twofold higher diuresis and creatinine clearance, (Table 3), respectively, ultimately resulting in lower creatinine, urea, and NGAL concentrations. HAM1101 caused a two- to tenfold reduction of the blood levels of IL-10 and the pro-inflammatory cytokines and chemokines, whereas $\mathrm{NO}_{2}^{-}+\mathrm{NO}_{3}^{-}$concentrations did not differ (Table 4).

Figure 2 shows the results of immune blotting and gel shifts: while NF- $\mathrm{BB}$ activation (Figure 2A) was comparable, HAM1101 attenuated the expression of HO-1 (Figure 2B) and activated caspase 3 (Figure $2 \mathrm{C}$ ). In contrast, Bcl-xL expression and the tail moment in the comet assay did not differ ( $p=0.149$ and 0.527 , respectively; data not shown). Figures 3 and 4 present typical kidney iNOS (Figure 3, upper panel) and nitrotyrosine (Figure 4, upper panel) immunostainings. Quantitative analysis (lower panel) showed that HAM1101 attenuated iNOS activation and nitrotyrosine formation. Figures 5, 6, and 7 present typical aortic eNOS (Figure 5, upper panel), iNOS (Figure 6, upper panel), and nitrotyrosine (Figure 7, upper panel) immunostainings. Image analysis demonstrates that HAM1101 attenuated iNOS activation and nitrotyrosine formation (Figures 6 and 7, lower panel), whereas eNOS expression was comparable (Figure 5, lower panel).

There was only minor kidney histological damage: glomerular tubularization was moderate without intergroup difference (vehicle: $13(12,14)$, HAM1101: $13(9,15) \%$ of glomerula analyzed, $p=0.724$ ), and neither tubular protein cylinders nor necrosis were found.

\section{Discussion}

The aim of this study was to test the hypothesis whether the ADM antibody HAM1101 may improve catecholamine responsiveness and attenuate kidney dysfunction during

Table 1 Plasma concentrations of mADM and HAM1101 in vehicle- $(n=11)$ and HAM1 101-treated $(n=9)$ animals

\begin{tabular}{lccc}
\hline & Vehicle & HAM1101 & $\boldsymbol{p}$ value \\
\hline mADM $\left(\mathrm{pg} \cdot \mathrm{mL}^{-1}\right)$ & $96(37,190)$ & $33(21,64)$ & 0.094 \\
HAM1101 $\left(\mu \mathrm{g} \cdot \mathrm{mL}^{-1}\right)$ & $\varnothing$ & $5.0(4.2,6.5)$ & $<0.001$ \\
\hline
\end{tabular}

Blood samples were taken at the end of the experiment. All data are median (quartiles). 


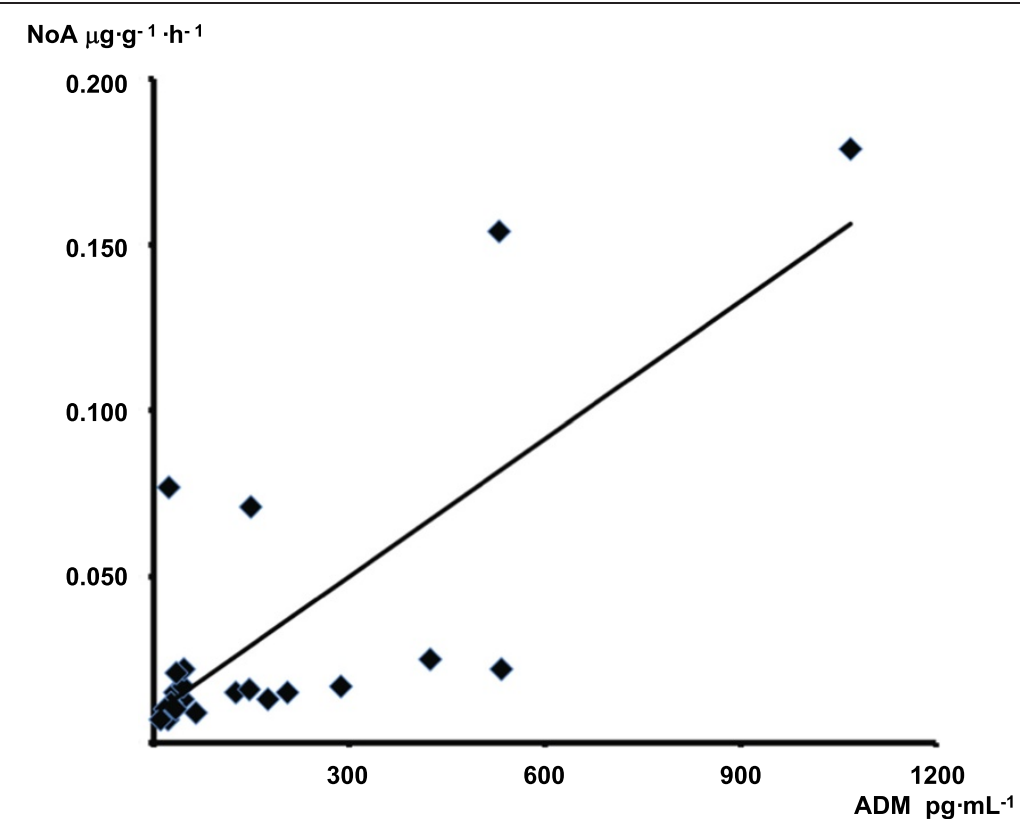

Figure 1 Mean noradrenaline $\left(\mathrm{NoA}, \boldsymbol{\mu g} \cdot \mathbf{g}^{-1} \cdot \mathbf{h}^{-1}\right)$ infusion rates. The infusion rates were plotted as a function of the blood adrenomedullin ( $\mathrm{ADM}, \mathrm{pg} \cdot \mathrm{mL}^{-1}$ ) concentrations in all 23 animals taken together, i.e., also taking into account the three animals excluded from the detailed statistical analysis because of abdominal bleeding and inadequate antibody activity. The Pearson coefficient of correlation was $r^{2}=0.574(p<0.001)$.

resuscitated murine CLP-induced septic shock. The major findings were that HAM1101 (1) reduced the catecholamine infusion rates needed to maintain target hemodynamics and (2) improved renal function, which was associated with (3) attenuated systemic inflammation, iNOS activation, and peroxynitrite formation, (4) ultimately resulting in reduced apoptosis.

In the HAM1101-treated mice, the lower noradrenaline requirements coincided with reduced aortic immunostaining for iNOS and nitrotyrosine, whereas eNOS expression was unchanged. This finding fits well with previous studies on the interaction of iNOS and ADM: in vascular smooth muscle cells, ADM aggravated the cytokine-induced iNOS activation and the excess NO release [23]. In vivo ADM increased myocardial and coronary endothelial nitrotyrosine formation, which was prevented by the NOS inhibitor $\mathrm{N}^{\mathrm{G}}$-nitro-L-arginine [32]. ADM antagonism reversed the lipopolysaccharide (LPS)-induced hypotension in rats [24], ultimately resulting in prolonged survival [25]. Furthermore, during rodent and human endotoxemia, hemodynamic stabilization with activated protein $\mathrm{C}$ was associated with lower blood NO and ADM levels [15]. Finally, we showed in CLP-induced septic shock that genetic deletion and selective pharmacological inhibition of iNOS improved catecholamine responsiveness: maintenance of target hemodynamics was achieved using lower noradrenaline infusion rates [29]. Nevertheless, our current findings may be regarded as in contrast to those of Talero et al. [8], who reported that ADM dose-dependently reduced iNOS expression, nitrotyrosine formation, NF- $\mathrm{kB}$ activation, pro-inflammatory cytokine concentrations, and attenuated histological injury in murine acute lung injury. We can only speculate on this discrepancy, but these authors used a short-term, un-resuscitated, sterile model in spontaneously breathing mice, whereas we investigated resuscitated polymicrobial 
Table 2 Lung mechanics, hemodynamics, gas exchange, acid-base status, and metabolic parameters

\begin{tabular}{|c|c|c|c|c|}
\hline & & Vehicle & HAM1101 & $p$ value \\
\hline \multirow[t]{2}{*}{ Hemoglobin content $\left(\mathrm{mg} \cdot \mathrm{mL}^{-1}\right)$} & Start & $90(87,96)$ & $98(95,105)$ & 0.074 \\
\hline & End & $70(66,72)$ & $69(66,74)$ & 0.806 \\
\hline \multirow[t]{2}{*}{ Heart rate (beats.min ${ }^{-1}$ ) } & Start & $494(485,515)$ & $430(406,480)$ & 0.248 \\
\hline & End & $426(406,445)$ & $391(349,430)$ & 0.290 \\
\hline \multirow[t]{2}{*}{ Mean arterial pressure $(\mathrm{mmHg})$} & Start & $69(65,71)$ & $69(66,76)$ & 0.382 \\
\hline & End & $64(59,69)$ & $67(66,72)$ & 0.441 \\
\hline \multirow[t]{2}{*}{ Thoracopulmonary compliance $\left(\mu \mathrm{L} \cdot \mathrm{cm} \mathrm{H}_{2} \mathrm{O}^{-1}\right)$} & Start & $0.10(0.09,0.10)$ & $0.10(0.09,0.11)$ & 0.382 \\
\hline & End & $0.09(0.08,0.10)$ & $0.10(0.08,0.11)$ & 0.427 \\
\hline \multirow[t]{2}{*}{ Arterial $\mathrm{PO}_{2}(\mathrm{mmHg})$} & Start & $314(293,330)$ & $340(321,350)$ & 0.254 \\
\hline & End & $309(287,326)$ & $301(287,319)$ & 0.838 \\
\hline \multirow[t]{2}{*}{ Arterial $\mathrm{PCO}_{2}(\mathrm{mmHg})$} & Start & $31(27,33)$ & $31(29,36)$ & 0.879 \\
\hline & End & $34(33,36)$ & $31(28,33)$ & 0.072 \\
\hline \multirow[t]{2}{*}{ Arterial pH } & Start & $7.33(7.30,7.35)$ & $7.36(7.32,7.38)$ & 0.569 \\
\hline & End & $7.38(7.31,7.43)$ & $7.43(7.39,7.46)$ & 0.253 \\
\hline \multirow[t]{2}{*}{ Arterial base excess $\left(\mathrm{mmol} \cdot \mathrm{mL}^{-1}\right)$} & Start & $-9.0(-10.3,-7.7)$ & $-6.8(-8.3,-6.2)$ & 0.403 \\
\hline & End & $-5.7(-7.1,-1.7)$ & $-3.9(-4.2,-3.3)$ & 0.838 \\
\hline \multirow[t]{2}{*}{ Arterial lactate $\left(\mathrm{mmol} \cdot \mathrm{mL}^{-1}\right)$} & Start & n.d. & n.d. & n.d. \\
\hline & End & $2.0(1.7,2.2)$ & $1.6(1.5,1.8)$ & 0.025 \\
\hline \multirow[t]{2}{*}{ Arterial glucose $\left(\mathrm{mg} \cdot \mathrm{dL}^{-1}\right)$} & Start & $113(110,117)$ & $115(106,123)$ & 0.540 \\
\hline & End & $110(96,117)$ & $111(109,115)$ & 0.653 \\
\hline \multirow[t]{2}{*}{$\mathrm{CO}_{2}$ production rate $\left(\mu \mathrm{L} \cdot \mathrm{g}^{-1} \cdot \mathrm{min}^{-1}\right)$} & Start & $26(24,28)$ & $24(23,25)$ & 0.082 \\
\hline & End & $23(21,26)$ & $23(22,25)$ & 0.596 \\
\hline \multirow[t]{2}{*}{ Glucose production rate $\left(\mathrm{mg} \cdot \mathrm{g}^{-1} \cdot \mathrm{h}^{-1}\right)$} & Start & $0.37(0.35,0.41)$ & $0.34(0.31,0.36)$ & 0.178 \\
\hline & End & $0.38(0.35,0.39)$ & $0.33(0.31,0.39)$ & 0.153 \\
\hline \multirow[t]{2}{*}{ Glucose oxidation rate (\% isotope infusion) } & Start & $58(55,62)$ & $55(50,59)$ & 0.224 \\
\hline & End & $57(54,60)$ & $62(58,67)$ & 0.047 \\
\hline
\end{tabular}

The data are for the vehicle-treated $(n=11)$ and HAM1101-treated $(n=9)$ animals at the start and the end of the 5-h observation period; n.d., not determined. All data are median (quartiles).

septic shock in anesthetized and mechanically ventilated animals. At first glance, the reduced cytokine concentrations seem to be in contrast with the unchanged NF- $\mathrm{kB}$ activation. The timing of the measurements most likely matters in this context: We obtained tissue samples at 20 to $22 \mathrm{~h}$ after induction of CLP, and we previously demonstrated that NF- $\mathrm{kB}$ activation was increased at 3 and $6 \mathrm{~h}$ and subsequently decreased at

Table 3 Parameters of kidney function in the vehicle- $(n=11)$ and HAM1101-treated $(n=9)$ animals

\begin{tabular}{lccc}
\hline & Vehicle & HAM1101 & $\boldsymbol{p}$ value \\
\hline Urine output $\left(\mu \mathrm{L} \cdot \mathrm{g}^{-1} \cdot \mathrm{h}^{-1}\right)$ & $4.4(3.5,16.5)$ & $15.2(13.9,22.5)$ & 0.033 \\
Creatinine clearance $\left(\mu \mathrm{L} \cdot \mathrm{min}^{-1}\right)$ & $197(110,301)$ & $400(316,509)$ & 0.006 \\
Creatinine $\left(\mu \mathrm{g} \cdot \mathrm{mL}^{-1}\right)$ & $1.83(1.52,3.04)$ & $1.28(1.20,1.52)$ & 0.010 \\
Urea $\left(\mu \mathrm{g} \cdot \mathrm{mL}^{-1}\right)$ & $378(268,513)$ & $175(101,184)$ & 0.004 \\
NGAL $\left(\mu \mathrm{g} \cdot \mathrm{mL}^{-1}\right)$ & $16(15,20)$ & $11(10,13)$ & 0.008 \\
\hline
\end{tabular}

Blood concentrations were measured in samples taken at the end of the experiment. NGAL, neutrophil gelatinaseassociated lipocalin. All data are median (quartiles). 
Table 4 Blood nitrite + nitrate $\left(\mathrm{NO}_{2}^{-}+\mathrm{NO}_{3}^{-}\right.$, in $\left.\mathrm{nmol} \cdot \mathrm{mL}^{-1}\right)$, cytokine, and chemokine concentrations

\begin{tabular}{lccc}
\hline & Vehicle & HAM1101 & $\boldsymbol{p}$ value \\
\hline $\mathrm{NO}_{2}^{-}+\mathrm{NO}_{3}^{-}$ & $111(59,121)$ & $92(47,93)$ & 0.170 \\
$\mathrm{TNF}-\mathrm{a}$ & $32(13,62)$ & $1(0,8)$ & 0.010 \\
$\mathrm{IL}-6$ & $363(120,681)$ & $43(22,55)$ & 0.002 \\
$\mathrm{IL}-10$ & $33(10,81)$ & $3(2,6)$ & 0.004 \\
$\mathrm{KC}$ & $2923(1873,7138)$ & $650(516,1577)$ & 0.016 \\
$\mathrm{MCP}-1$ & $1130(779,1738)$ & $509(335,614)$ & 0.005 \\
\hline
\end{tabular}

The data are for vehicle-treated $(n=11)$ and HAM1101-treated $(n=9)$ animals. Blood samples were taken at the end of the experiment. TNF- $a$, tumor necrosis factor- $a$; IL-6, interleukin-6; IL-10, interleukin-10; KC, keratinocyte-derived chemokine; MCP-1, monocyte chemoattractant protein-1. All parameters are in $\mathrm{pg} \cdot \mathrm{mL}^{-1}$. All data are median (quartiles).

12 and $36 \mathrm{~h}$ after CLP induction [33]. It is well established that NF-KB activation triggers not only inflammation but also its resolution [34], and the present finding well agrees with previous data on the effect of combining $\mathrm{Na}_{2} \mathrm{~S}$ and hypothermia in the same model: the lowest pro-inflammatory cytokine plasma and tissue concentrations and the highest blood IL-10 levels coincided with the maximum NF-kB activation [27].

Interestingly, HAM1101 reduced iNOS expression and nitrotyrosine formation but did not affect vascular eNOS expression. Moreover, ADM plasma concentrations were not significantly reduced either, the mean value in the HAM1101-treated animals being five times higher than in mice without surgery. This finding fits with Gupta et al.

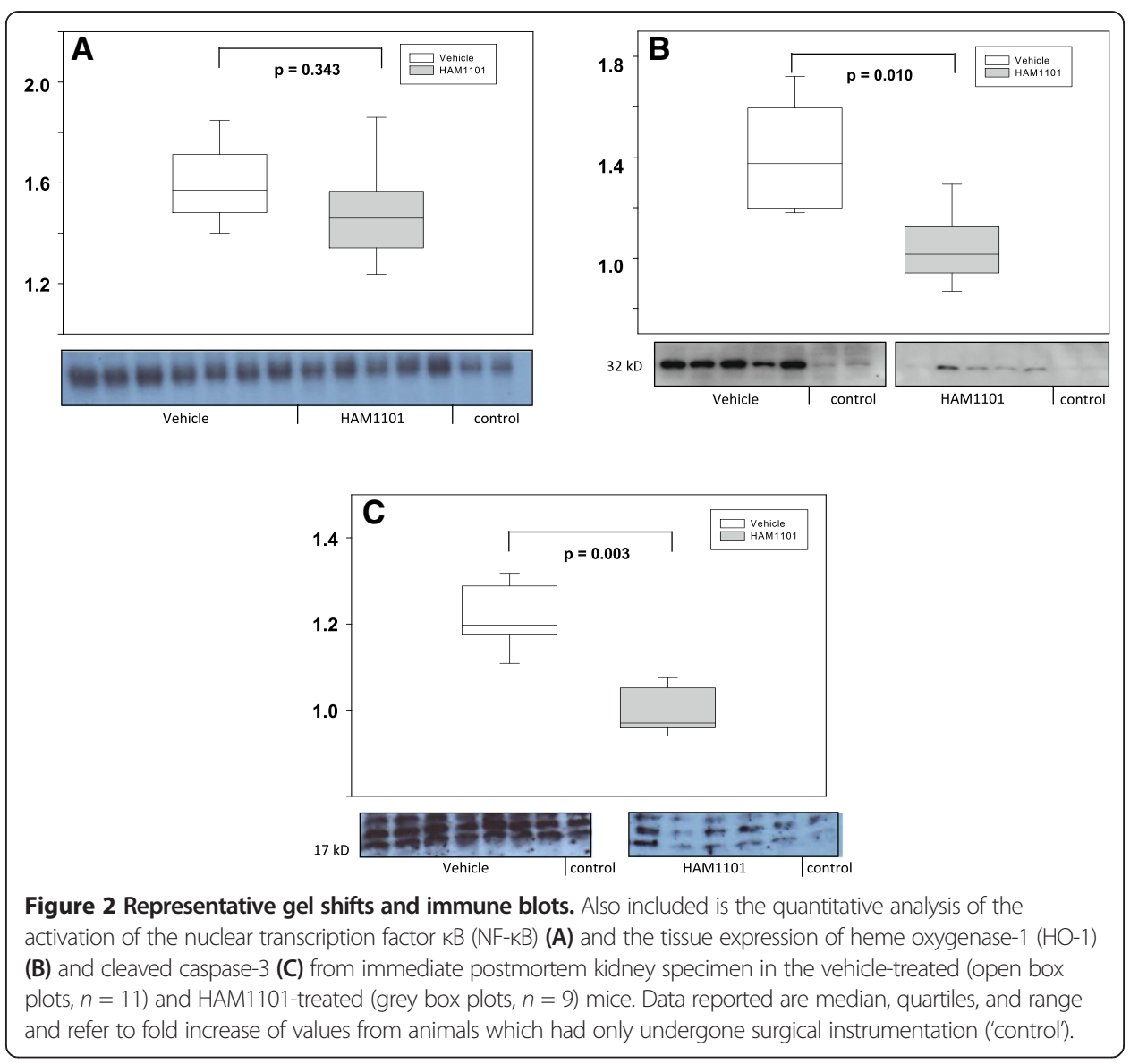



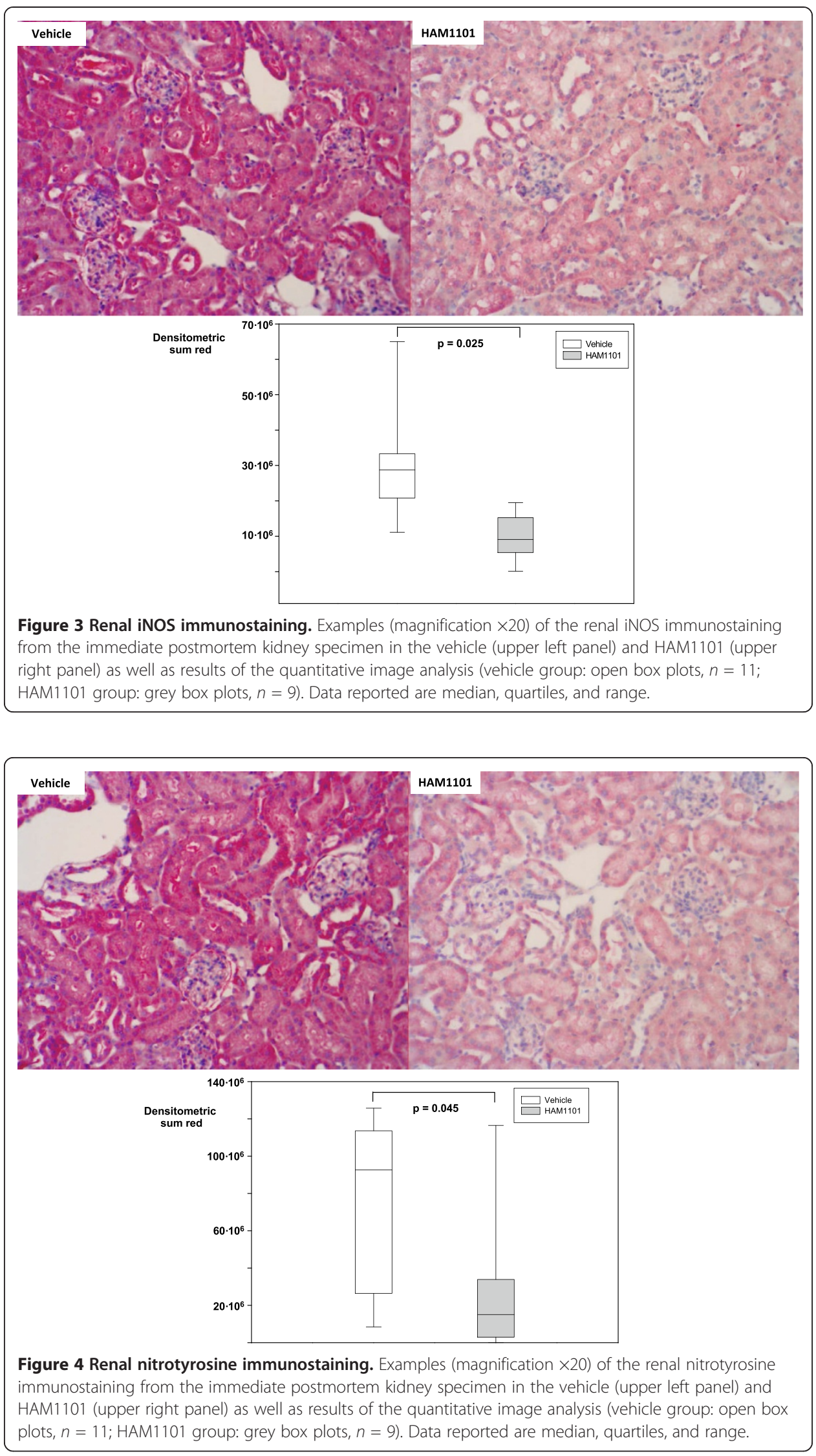


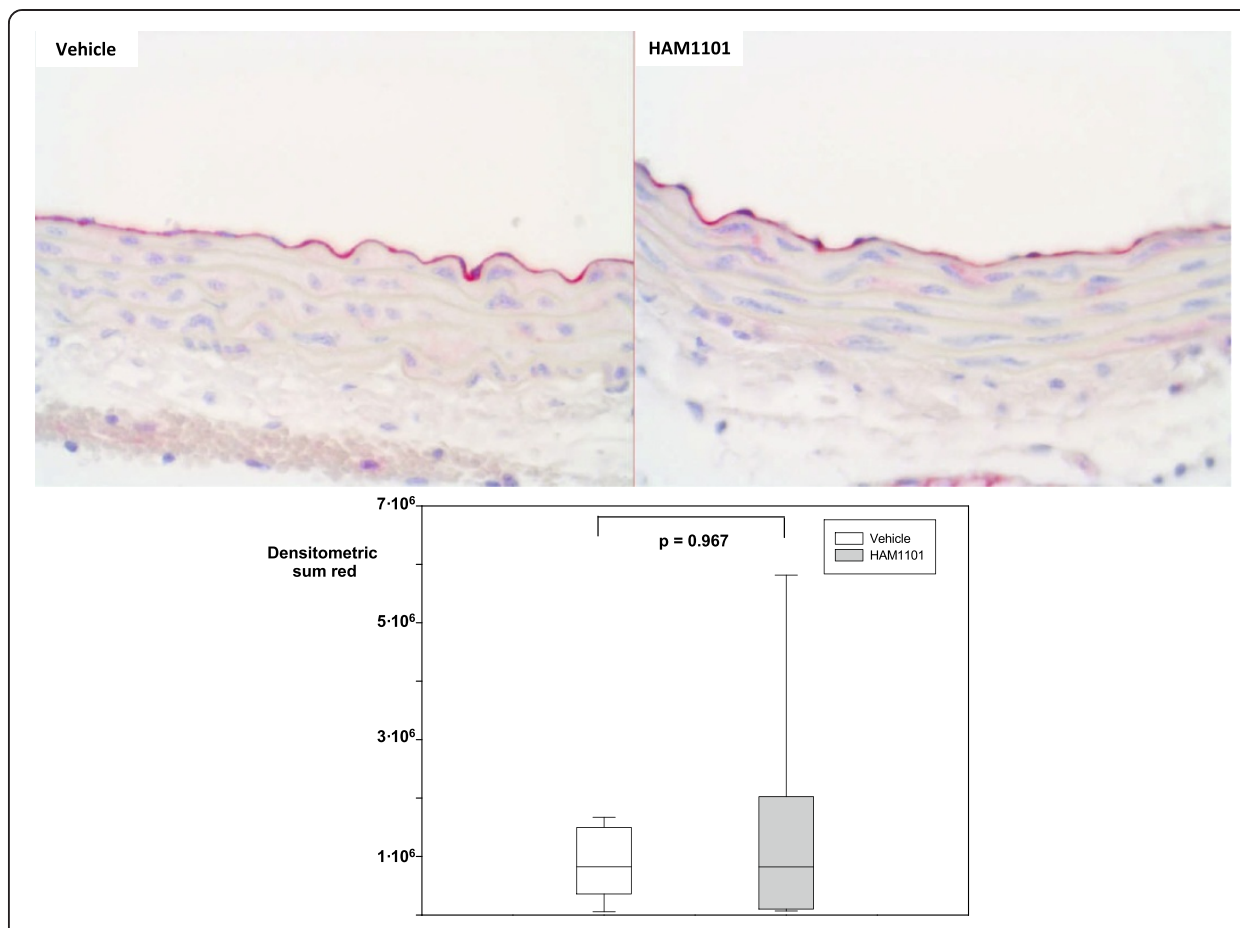

Figure 5 Thoracic aortic eNOS immunostaining. Examples (magnification $\times 40$ ) of the thoracic aortic eNOS immunostaining from the immediate postmortem kidney specimen in the vehicle (upper left panel) and HAM1 101 (upper right panel) as well as results of the quantitative image analysis (intima layer; vehicle group: open box plots, $n=11$; HAM1 101 group: grey box plots, $n=9$ ). Data reported are median, quartiles, and range.

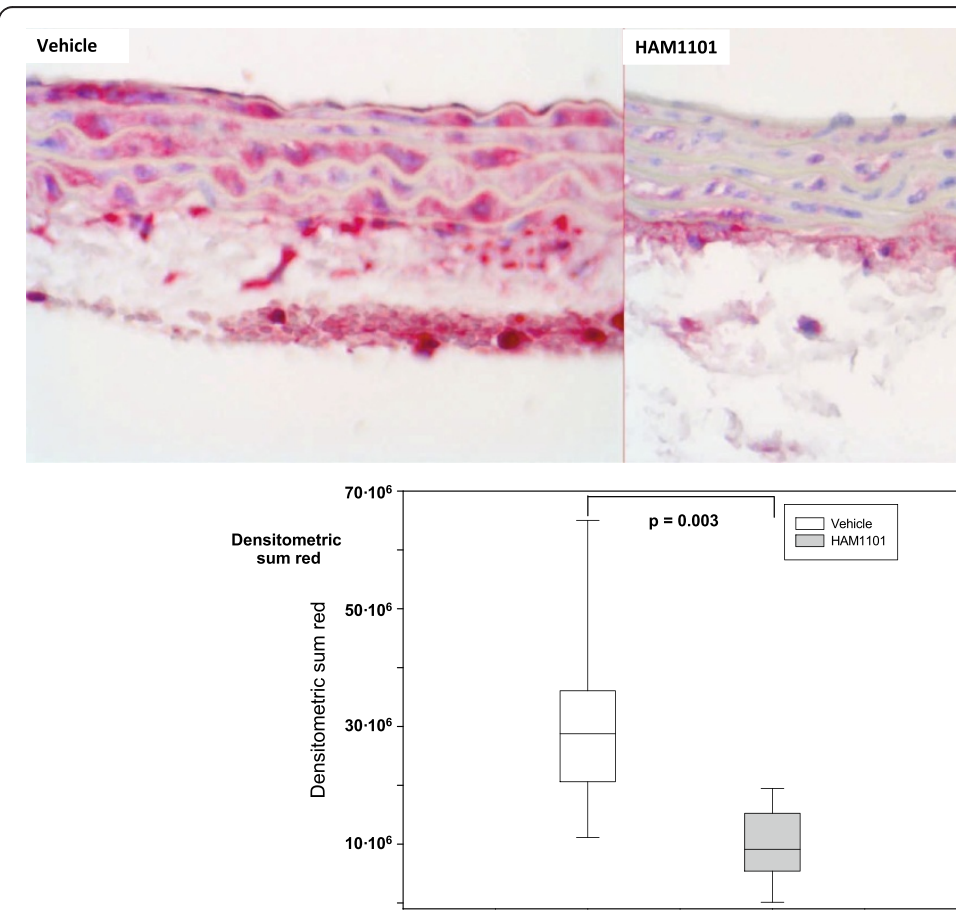

Figure 6 Thoracic aortic iNOS immunostaining. Examples (magnification $\times 40$ ) of the thoracic aortic iNOS immunostaining from the immediate postmortem kidney specimen in the vehicle (upper left panel) and HAM1101 (upper right panel) as well as results of the quantitative image analysis (intima plus media layer; vehicle group: open box plots, $n=11$; HAM1101 group: grey box plots, $n=9$ ). Data reported are median, quartiles, and range. 


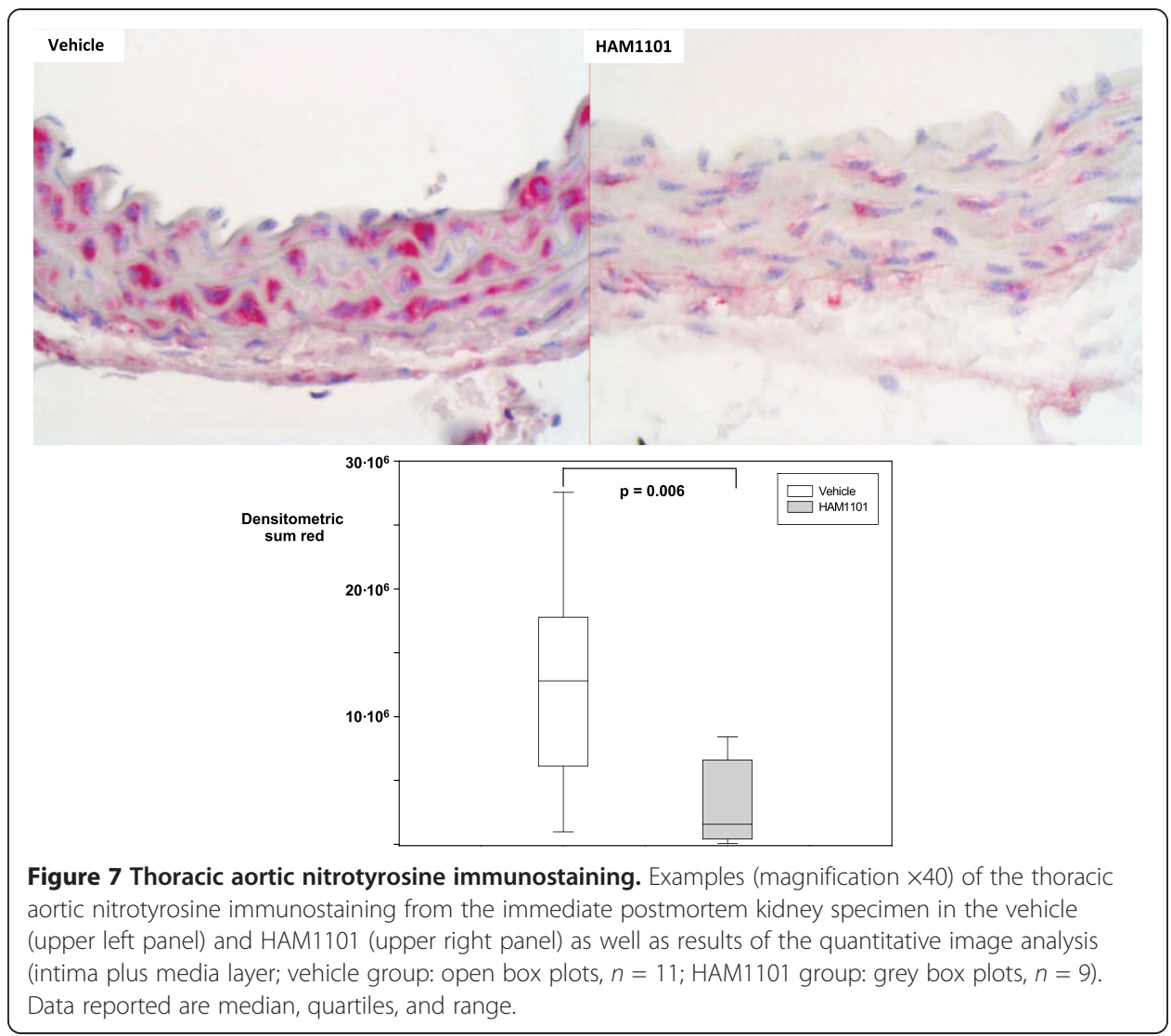

reporting that the salutary effect of activated protein $\mathrm{C}$ in rats was not associated with complete reversal of the LPS-induced increase in blood NO and ADM levels [15]. It is tempting to speculate that HAM1101 attenuated excess NO and ADM formation rather than completely blocking it while maintaining the constitutive production necessary for organ homoeostasis $[9,12]$. Clearly, the attenuated iNOS activation is not mirrored by reduced $\mathrm{NO}_{2}^{-}+\mathrm{NO}_{3}^{-}$levels. Because of the limited blood volume available, these values were only obtained at the end of the experiment, i.e., at approximately 22 $\mathrm{h}$ after CLP induction. Hence, this finding well fits with previous studies by others and ourselves that $\mathrm{NO}_{2}^{-}+\mathrm{NO}_{3}^{-}$concentrations were comparable at 18 to $24 \mathrm{~h}$ post-CLP in mice with ascorbate- [35] or GW274150-induced iNOS inhibition [29] and peroxynitrite blockade [36].

We did not measure the degree of interstitial edema; however, the threefold higher urine output together with the identical fluid administration rates and total hemoglobin content suggest that HAM1101 attenuated a possible ADM-related fluid extravasation [37]. Consequently, HAM1101 most likely allowed for better maintenance of circulating blood volume. The higher urine output coincided with improved creatinine clearance and lower blood creatinine, urea, and NGAL levels. This evidence of improved glomerular and tubular function [38] was associated with reduced iNOS expression and nitrotyrosine formation, a well-established marker of peroxynitrite formation. Both iNOS activation and peroxynitrite production play a crucial role for acute kidney injury: selective iNOS blockade and catalytic peroxynitrite decomposition attenuated kidney dysfunction and organ damage in murine CLP-induced sepsis [36,39,40]. It could be 
argued that the improved renal function is not mirrored by kidney histology: in fact, tubular necrosis was absent, and glomerular tubularization was only moderate. Nonetheless, the reduced expression of activated caspase 3 suggests less apoptosis. Moreover, we investigated anesthetized and mechanically ventilated mice receiving fluid resuscitation and noradrenaline to maintain normotensive hemodynamics: in un-resuscitated murine CLP-induced septic shock of comparable duration (18 to $20 \mathrm{~h}$ ), histological damage coincided with five- to tenfold higher creatinine and urea blood levels [41]. Finally, more advanced glomerular tubularization was present only after 2 to 3 days and severe kidney dysfunction with at least ten times higher creatinine levels [38].

Albeit noradrenaline infusion rates were lower; HAM1101 was associated with comparable endogenous glucose production. Together with the reduced iNOS expression, this finding is in line with our previous study in mice with genetic deletion and selective pharmacological inhibition of iNOS: hepatic gluconeogenesis was comparable despite lower noradrenaline infusion rates, indicating improved hepatic metabolic performance [42]. HAM1101 was associated not only with well-maintained glucose formation but also with a higher direct, aerobic glucose oxidation rate. We could not measure wholebody $\mathrm{O}_{2}$ uptake, but together with the identical total $\mathrm{CO}_{2}$ production and the comparable endogenous glucose production rate, this finding indicates that HAM1101 caused a preferential use of glucose for energy metabolism. Such a switch in fuel utilization is associated with an improved yield of oxidative phosphorylation [43]: The ratio of ATP synthesis/oxygen consumption ratio is higher for glycolysis than for $\beta$-oxidation because nicotinamide adenine dinucleotide (NADH) as an electron donor provides three coupling sites rather than two only from flavin adenine dinucleotide $\left(\mathrm{FADH}_{2}\right)$ [44].

\section{Limitations of the model}

HAM1101 was administered immediately after the CLP procedure. Hence, HAM1101 may only be efficacient when administered during the very early phase of sepsis. Consequently, further studies are warranted on the time dependency of the HAM1101 treatment.

All mice needed noradrenaline to maintain target hemodynamics. Consequently, any beneficial effects of HAM1101 may have been caused by ADM binding per se or due to this reduction in catecholamine requirements: noradrenaline may exert cardio- and hepatotoxic effects, enhance systemic inflammation and promote oxidative stress, and impair mitochondrial respiration.

\section{Conclusions}

During resuscitated, polymicrobial, murine septic shock, early ADM binding using the newly developed N-terminal anti-ADM antibody HAM1101 improved catecholamine responsiveness and blunted the shock-related impairment of energy metabolism ultimately coinciding with attenuated kidney dysfunction and organ injury. These beneficial effects of HAM1101 resulted from attenuation of the systemic inflammatory response and reduced nitrosative stress while constitutive NO synthesis was unaffected.

\section{Additional file}

Additional file 1: Supplement. Adrenomedullin (ADM) and ADM antibody (HAM1101) preparation. 


\section{Competing interests}

FH and AB are employed by AdrenoMed AG and hold shares of AdrenoMed AG. AdrenoMed AG holds patent rights on anti-ADM antibodies. PR received an unrestricted research grant from Adrenomed AG. The other authors declare that they have no competing interests.

\section{Authors' contributions}

$P R, K W, F W, E C, F H$, and $A B$ conceived the study and designed the experiment. MG, KW, and SW were responsible for anesthesia and surgery as well as data acquisition and statistical analysis. OM, ASch, and PM were responsible for histology and immunohistochemistry analyses, and KW and BS for western blotting and gel shifts. JA and UW performed the isotope measurements and data analyses. PR, MGe, FW, PM, FH, and AB drafted the manuscript. All authors read and approved the final manuscript.

\section{Acknowledgements}

We are indebted to Marina Fink, Rosemarie Mayer, and Tanja Schulz for skillful technical assistance. This study was supported by an unrestricted grant from Adrenomed AG, Hennigsdorf, Germany and by Project Grants of the Federal State of Brandenburg and European Regional Development Funds (EFRE).

\section{Author details}

${ }^{1}$ Sektion Anästhesiologische Pathophysiologie und Verfahrensentwicklung, Klinik für Anästhesiologie, Ulm 89081, Germany. ${ }^{2}$ Institut für Pathologie, Universitätsklinikum, Albert-Einstein-Allee 23, Ulm 89081, Germany. ${ }^{3}$ Adrenomed AG, Hennigsdorf 16761, Germany.

Received: 9 October 2013 Accepted: 10 October 2013

Published: 29 October 2013

\section{References}

1. Mittra S, Hyvelin JM, Shan Q, Tang F, Bourreau JP (2004) Role of cyclooxygenase in ventricular effects of adrenomedullin: is adrenomedullin a double-edged sword in sepsis? Am J Physiol Heart Circ Physiol 286: $\mathrm{H} 1034-\mathrm{H} 1042$

2. Wang P, Ba ZF, Cioffi EG, Bland Kl, Chaudry IH (1998) The pivotal role of adrenomedullin in producing hyperdynamic circulation during the early stage of sepsis. Arch Surg 133:1298-1304

3. Yang S, Zhou M, Chaudry $H$, Wang P (2002) Novel approach to prevent the transition from the hyperdynamic phase to the hypodynamic phase of sepsis. Role of adrenomedullin and adrenomedullin binding protein-1. Ann Surg 236:625-633

4. Wu R, Higuchi S, Dong W, Ji Y, Zhou M, Marini CP, Ravikumar TS, Wang P (2009) Reversing established sepsis in rats with human vasoactive hormone adrenomedullin and its binding protein. Mol Med 15:28-33

5. Ertmer C, Morelli A, Rehberg S, Lange M, Hucklenbruch C, Van Aken H, Booke M, Westphal M (2007) Exogenous adrenomedullin prevents and reverses hypodynamic circulation and pulmonary hypertension in ovine endotoxaemia. Br J Anaesth 99:830-836

6. Temmesfeld-Wollbrück B, Brell B, Dávid I, Dorenberg M, Adolphs J, Schmeck B, Suttorp N, Hippenstiel S (2007) Adrenomedullin reduces vascular hyperpermeability and improves survival in rat septic shock. Intensive Care Med 33:703-710

7. Yang S, Zhou M, Fowler DE, Wang P (2002) Mechanisms of the beneficial effect of adrenomedullin and adrenomedullin-binding protein-1 in sepsis: down-regulation of proinflammatory cytokines. Crit Care Med 30:2729-2735

8. Talero E, Di Paola R, Emanuela M, Esposito E, Virginia M, Cuzzocrea S (2012) Anti-inflammatory effects of adrenomedullin on acute lung injury induced by carrageenan in mice. Mediators Inflamm 2012:177851

9. Zhou M, Maitra SR, Wang P (2007) Adrenomedullin and adrenomedullin binding protein-1 protect endothelium-dependent vascular relaxation in sepsis. Mol Med 13:488-494

10. Zhou M, Simms HH, Wang P (2004) Adrenomedullin and adrenomedullin binding protein-1 attenuate vascular endothelial cell apoptosis in sepsis. Ann Surg 240:321-330

11. Zudaire E, Portal-Núñez S, Cuttitta F (2006) The central role of adrenomedullin in host defense. J Leukoc Biol 80:237-244

12. Fowler DE, Wang P (2002) The cardiovascular response in sepsis: proposed mechanisms of the beneficial effect of adrenomedullin and its binding protein (review). Int J Mol Med 9:443-449

13. Roch A (2009) Increased levels of pro-AVP and pro-ADM in septic shock patients: what could it mean? Intensive Care Med 35:1827-1829

14. Westphal M, Stubbe H, Bone HG, Daudel F, Vocke S, Van Aken H, Booke M (2002) Hemodynamic effects of exogenous adrenomedullin in healthy and endotoxemic sheep. Biochem Biophys Res Commun 296:134-138

15. Gupta A, Berg DT, Gerlitz B, Richardson MA, Galbreath E, Syed S, Shrama AC, Lowry SF, Grinnell BW (2007) Activated protein c suppresses adrenomedullin and ameliorates lipopolysaccharide-induced hypotension. Shock 28:468-476

16. Nishio K, Akai Y, Murao Y, Doi N, Udea S, Tabuse H, Miyamoto S, Dohi K, Minamino N, Shoji H, Kitamura K, Kangawa K, Matsuo H (1997) Increased plasma concentrations of adrenomedullin correlate with relaxation of vascular tone in patients with septic shock. Crit Care Med 25:953-957

17. Hirata Y, Mitaka C, Sato K, Nagura T, Tsunoda Y, Amaha K, Marumo F (1996) Increased circulating adrenomedullin, a novel vasodilatory peptide, in sepsis. J Clin Endocrinol Metab 81:1449-1453

18. Ueda S, Nishio K, Minamino N, Kubo A, Akai Y, Kangawa K, Matsuo H, Fujimura Y, Yoshioka A, Masui K, Doi N, Murao Y, Miyamoto S (1999) Increased plasma levels of adrenomedullin in patients with systemic inflammatory response syndrome. Am J Respir Crit Care Med 160:132-136 
19. Christ-Crain M, Morgenthaler NG, Struck J, Harbarth S, Bergmann A, Müller B (2005) Mid-regional pro-adrenomedullin as a prognostic marker in sepsis: an observational study. Crit Care 9:R816-R824

20. Christ-Crain M, Morgenthaler NG, Stolz D, Müller C, Bingisser R, Harbarth S, Tamm M, Struck J, Bergmann A, Müller B (2006) Pro-adrenomedullin to predict severity and outcome in community-acquired pneumonia. Crit Care 10:R96

21. Guignant C, Voirin N, Venet F, Poitevin F, Malcus C, Bohé J, Lepape A, Monneret G (2009) Assessment of pro-vasopressin and pro-adrenomedullin as predictors of 28-day mortality in septic shock patients. Intensive Care Med 35:1859-1867

22. Guignant C, Voirin N, Venet F, Lepape A, Monneret G (2012) Persistent high level of circulating midregionalproadrenomedullin and increased risk of nosocomial infections after septic shock. J Trauma 72:293-296

23. Hattori Y, Nakanishi N, Gross SS, Kasai K (1999) Adrenomedullin augments nitric oxide and tetrahydrobioptein synthesis in cytokine-stimulated vascular smooth muscle cells. Cardiovasc Res 44:207-214

24. Mazzocchi G, Albertin G, Nussdorfer GG (2000) Adrenomedullin (ADM), acting through ADM(22-52)-sensitive receptors, is involved in the endotoxin-induced hypotension in rats. Life Sci 66:1445-1450

25. Hyvelin JM, Shan Q, Bourreau JP (2002) Adrenomedullin: a cardiac depressant factor in septic shock. J Card Surg 17:328-335

26. Hollenberg SM, Broussard M, Osman J, Parrillo JE (2000) Increased microvascular reactivity and improved mortality in septic mice lacking inducible nitric oxide synthase. Circ Res 86:774-778

27. Wagner F, Wagner K, Weber S, Stahl B, Knöferl MW, Huber-Lang M, Seitz DH, Asfar P, Calzia E, Senftleben U, Gebhard F, Georgieff M, Radermacher P, Hysa V (2011) Inflammatory effects of hypothermia and inhaled $\mathrm{H}_{2} \mathrm{~S}$ during resuscitated, hyperdynamic murine septic shock. Shock 35:396-402

28. Wagner F, Scheuerle A, Weber S, Stahl B, McCook O, Knöferl MW, Huber-Lang M, Thomas J, Asfar P, Szabó C, Möller P, Gebhard F, Georgieff M, Calzia E, Radermacher P, Wagner K (2011) Cardiopulmonary, histologic, and inflammatory effects of intravenous $\mathrm{Na}_{2} \mathrm{~S}$ after blunt chest trauma-induced lung contusion in mice. J Trauma 71:1659-1667

29. Barth E, Radermacher P, Thiemermann C, Weber S, Georgieff M, Albuszies G (2006) Role of iNOS in the reduced responsiveness of the myocardium to catecholamines in a hyperdynamic, murine model of septic shock. Crit Care Med 34:307-313

30. Baumgart K, Wagner F, Gröger M, Weber S, Barth E, Vogt JA, Wachter U, Huber-Lang M, Knöferl MW, Albuszies G, Georgieff M, Asfar P, Szabó C, Calzia E, Radermacher P, Simkova S (2010) Cardiac and metabolic effects of hypothermia and inhaled $\mathrm{H}_{2} \mathrm{~S}$ in anesthetized and ventilated mice. Crit Care Med 38:588-595

31. Isaac J, Tögel FE, Westenfelder C (2007) Extent of glomerular tubularization is an indicator of the severity of experimental acute kidney injury in mice. Nephron Exp Nephrol 105:e33-e40

32. Loi YH, Kane KA, McPhaden AR, Wainwright CL (2006) Adrenomedullin acts via nitric oxide and peroxynitrite to protect against myocardial ischaemia-induced arrhythmias in anaesthetized rats. Br J Pharmacol 148:599-609

33. Groesdonk HV, Wagner F, Hoffarth B, Georgieff M, Senftleben U (2007) Enhancement of NF-KB activation in lymphocytes prevents T cell apoptosis and improves survival in murine sepsis. J Immunol 179:8083-8089

34. Lawrence T, Bebien M, Liu GY, Nizet V, Karin M (2005) IKKa limits macrophage NF-KB activation and contributes to the resolution of inflammation. Nature 434:1138-1142

35. Wu F, Wilson JX, Tyml K (2003) Ascorbate inhibits iNOS expression and preserves vasoconstrictor responsiveness in skeletal muscle of septic mice. Am J Physiol Regul Integr Comp Physiol 285:R50-R56

36. Wang Z, Holthoff JH, Seely KA, Pathak E, Spencer HJ, Gokden N, Mayeux PR (2012) Development of oxidative stress in the peritubular capillary microenvironment mediates sepsis-induced renal microcirculatory failure and kidney injury. Am J Pathol 180:505-516

37. Kaufmann S, Andrew P, Sultanian R, Deng Y (2001) Adrenomedullin increases fluid extravasation from the splenic circulation of the rat. J Physiol 534:527-533

38. Kuwabara T, Mori K, Mukoyama M, Kasahara M, Yokoi H, Saito Y, Yoshioka T, Ogawa Y, Imamaki H, Kusakabe T, Ebihara K, Omata M, Satoh N, Sugawara A, Barasch J, Nakao K (2009) Urinary neutrophil gelatinase-associated lipocalin levels reflect damage to glomeruli, proximal tubules, and distal nephrons. Kidney Int 75:285-294

39. Wu L, Gokden N, Mayeux PR (2007) Evidence for the role of reactive nitrogen species in polymicrobial sepsis-induced renal peritubular capillary dysfunction and tubular injury. J Am Soc Nephrol 18:1807-1815

40. Soriano FG, Lorigados CB, Pacher P, Szabó C (2011) Effects of a potent peroxynitrite decomposition catalyst in murine models of endotoxemia and sepsis. Shock 35:560-566

41. Wang Z, Herzog C, Kaushal GP, Gokden N, Mayeux PR (2011) Actinonin, a meprin A inhibitor, protects the renal microcirculation during sepsis. Shock 35:141-147

42. Albuszies G, Vogt J, Wachter U, Thiemermann C, Leverve XM, Weber S, Georgieff M, Radermacher P, Barth E (2007) The effec of iNOS deletion on hepatic gluconeogenesis in hyperdynamic murine septic shock. Intensive Care Med 33:1094-1101

43. Korvald C, Elvenes OP, Myrmel T (2000) Myocardial substrate metabolism influences left ventricular energetics in vivo. Am J Physiol Heart Circ Physiol 278:H1345-H1351

44. Leverve XM (2007) Mitochondrial function and substrate availability. Crit Care Med 35(suppl):S454-S460

doi:10.1186/2197-425X-1-2

Cite this article as: Wagner et al:: Adrenomedullin binding improves catecholamine responsiveness and kidney function in resuscitated murine septic shock. Journal of Software Engineering Research and Development 2013 1:2. 